\title{
Evaluation of Relationship between Social Support and Social Health of Tehran Citizens
}

\author{
Habib Sabouri Khosro Shahi ${ }^{1} \&$ Somayeh Mashayekhi ${ }^{2}$ \\ ${ }^{1}$ Islamic Azad University, East Tehran Branch, Tehran, Iran \\ ${ }^{2}$ Center Tehran Branch, Tehran, Iran \\ Correspondence: Somayeh Mashayekhi, Center Tehran Branch, Tehran, Iran. E-mail: \\ mashayekhisogol@yahoo.com
}

Received: January 16, 2017

Accepted: January 30, 2017

Online Published: May 16, 2017

doi:10.5539/res.v9n2p275

URL: http://doi.org/10.5539/res.v9n2p275

\begin{abstract}
Social health is a concept that is created from relationship between two concepts of health and society. Since the society is a nominal concept and its external truth depends on everyone who has formed it, in evaluation of society, people of that should be evaluated and studied more than everything. In this regard the present research under the topic of "Evaluation of relationship between social support and social health of Tehran citizens" has been conducted among Tehran citizens in 2016. Social health was evaluated based on Keyes's theories in five dimensions of social prosperity, social adaptation, social cohesion, social acceptance and social participation and also social support was evaluated based on researches of Wax et al. in three dimensions of friends support, family support and others support. Research methodology in this research is survey and technique of data collection is questionnaire. The questionnaires were distributed among 400 people of women who were selected as multi-stage cluster sampling, and because 15 of questionnaires were altered, approximately 385 were finally analyzed. The result was that social support is one of effective factors on social health; the obtained adjusted multiple coefficient of determination showed that the triple dimensions of social support (friends support, family support and others support) have been able to express approximately $58 \%$ of the social health variable.
\end{abstract}

Keywords: social health, social support, friends support, family support and others support

\section{Introduction}

The health issue had been raised from the beginning the dawn of mankind and in the consecutive centuries. But when it has been expressed generally the physical dimension of that has been considered and less attention has been paid to other dimensions of health especially social dimension. The World Health Organization has been identified the social health as one of levels of person's overall health in 1948. Concept of social health is a concept that has been considered beside physical and mental dimensions of health and its social aspect is evaluated by focus on person. Health is a word that although most people are confident that know the meaning of that but they find its definition difficult. So health has been defined in different ways in different periods. A definition that has been accepted more than all is definition of the World Health Organization (1948) that knows health including complete physical, mental and social welfare, not just being not sick or disabled. This definition considers three physical, mental and social dimensions for health. The social dimension of health includes levels of social skills, social operation and ability to identify each person from self as a member of the greater society.

Social health mentions to way of situation of person's relationship with others in society or sociability of him and it emphasizes on dimensions of health that are related to relationship of person with other people or a society that he lives in (Larson, 1996, p. 186). According to Keyes's opinion (2004) the lost ring in history of researches is related to this question; is it possible to people evaluate their personal life quality or personal operation without consideration to social criteria? Keyes to answer this question poses the concept of social health means person's evaluation from his operation to society, as one of important dimensions of health (Keyes \& Shapiro, 2004, pp. 33-41).

Durability and survival of humans' life partly depend on quality of people's social health. This quality greatly is affected by cultural condition and its components such asthe attitude of people from life such as be happy and living happy, links and social support of people from each other, life without much stresses, trust, cooperation 
and as much as possible free of destructive and apparent conflicts in terms of gender, generational, ethnic, religious and class. All these factors are greatly affected by objective condition of society, available bases and even people's perceptions from existing situation and way of their attitude and judgment that can be intensified in an unsuitable cultural base that finally can jeopardize quality of social health of a society.

According to comment of commission of mental-social determinative factors of WHO health; approximately $85 \%$ of factors are effective on health system expect biological and genetic factors that seems they have been ignored in all countries such as Iran. Although there aren't same definitions and indexing for social health; but certain indexes have been used proportional to each region.

From viewpoint of experts in Iran indexes of social health include: not being poor person, violence, sex discrimination, unemployment and ethno-racial-regional discrimination; controlling population growth, equality before the law, respect for human rights treaties and other treaties related to human rights, free and compulsory education up to the end of the secondary school, public access to health services; existing security and freedom of opinion, life satisfaction, being all people under cover of insurance; equitable distribution of incomes (right of people to be given and all have equal opportunity to earn income); legitimacy of government with the people, selecting rulers democratically and supervision of people on them (Rafiei, Samiei, Amini, \& Akbarian, 2010).

Results of many researches show that amount of social health is passing descending trend in Iran. In evaluation of mental health of Tehran city, prevalence of mental disorders was estimated $34.2 \%$ (37.9\% female and $28.6 \%$ male) (Noorbala, Bagheri, Asadi, \& Vaez, 2011; Noorbala, Bagheri, \& Mohammad, 2009).

Statistic of mental disorders doesn't have good situation in Iran compared with other countries. In Iran married people don't have better mental health than single people for different reasons and increasing trend of divorce statistic is alarming in urban and village that it shows the existence of problem and damage in family and at least disorder in interpersonal relationships. Unstoppable, but growing trend of incidence of addiction phenomenon in Iran, despite all conducted serious deals before and after the revolution, shows the failure of the conducted acts. Addiction has been changed to mental-social damaging important issue of the country.

Based on the cases which were mentioned in above, if no fundamental and basic action is formed in the prevention dimension of stressful factors in the level of family and society, an unpleasant future is predicted for the country that not only the mental health but also it will endanger social health of people. From another hand urban life and issues related to urbanization, routine, work issues and job security which are important issues of today's urban life in Iran, are predisposing jeopardizing social health of people. In this regard, the present research is trying to answer these questions: 1) how much is the amount of social health among Tehran citizens? 2) how is the relationship of social support and social health?

\section{Conceptual Circulation}

Health is a word that although most people are confident that know the meaning of that but they find its definition difficult. Health word is retrieved from English world of heal that shows well-being issues of complete person, integrity, authenticity and comfort of him. Health definition in each society returns to people's common feeling from their health and culture and there are different perceptions from that in different communities and groups (Sadegh, 1996, p. 36).

Empirically the concept of social health has root insociological literature related to social alienation and anomalies. Social health evaluates way of relationship situation between person and society; in a way that if people are not adapted to social frameworks, it will be an anomic and favorable filed for development of social deviations. In such case a type of extreme individualism situates individual requests against social life (Akbarian et al., 2010, p. 97). Root of social health is in "positive corporeal environment" (means paying attention to economic and residential issues) and "positive human environment" that considers social net of person (Kangar Loo, 2008, p. 24).

Social health is a type of mental, personal and social health that if it becomes true in society; citizens have motivation and happy morale and finally the society will be succulent and healthy. In fact the healthy life is product of social interaction between individual choices from a side and social and economic environment circumfluent of people from another side. Social health in life in fact is the same evaluations and positive and negative attitudes of people from others who they are in social interaction with them in their routine life.

"Social health is a part of person's health that is appeared in society arena. We consider the person with social health when be able to appear his activities and social roles in the usual level and feel connection and link with society and social norms" (Sam, 2009, p. 24). Also existence of relationship between people orsociability covers enjoying being among friends, supporting from family, relatives and friends that communication and 
interferometry are done in a same economic-social class (Sajjadi \& Sadrossadat, 2004, p. 246).

Social health is a different amount from viewpoint of researchers who are active in America. They have preferred "mental-social health" term to this word and also mention its reason the measurability of that, but European researches still emphasize on "social health" word. The best definition that Europeans have been presented from this concept is "the main base of social health is social support" (Sabouri, 2011, p. 23).

Health is reflection of condition of society's people. Health is derived from social and economic factors and intervention in these factors is beyond the medical profession. James found "character or social self" is formed in social relationships, bases and roles that person takes (Tavassoli, 1990, p. 27).

Social health mentions way of person's communication with others or sociability of him. In Durkheim's opinion each type of disconnection between person and society in a way that people are not attracted to social frameworks is an anomic and favorable field for development of social deviations. In such case a type of extreme individualism situates individual requests against social life (Tavassoli, 2003, p. 71).

Also each kind of abyss or distance between person and society that ends to not integrating people in social frameworks, makes favorable field forsocial deviations. Furthermore social relationships (relationship of person with others in society) in addiction to supply types of support, provides a field for intimacy and dependency. Intimacy and dependency are not meaningful only inkinship relationships, but also it is meaningful about external connections too; for example when relationships to bestrong and coherent in social level, people feel dependency and fixation to places (neighbors and neighborhoods) and organizations (religious organizations and voluntary associations) and make intimate relationships with people who live in such places and places (Kangar Loo, 2008, p. 23).

In Hilz's opinion when social health is defined, without realization of its physical and mental dimensions, this dimension of health will be not supplied. In his viewpoint social health is referred to person's ability in effective interaction with others in order to make personal fulfilling relationships and do social roles that includes social participation, compatible life with other humans, making positive relationships relying on each other and having healthy sexual relationships (quoted by Zahedi, 1997, p. 172).

Ustun and Jakob (2005) have known social health including levels of social skills, social operation and ability to identify each person from self as a member of the greater society and they have paid attention to economic and social condition, welfare andintegrity of person in his social net (Rafiei et al., 2010, p. 29).

Larson defines social health as person's evaluation from quality of his relationships with family, others and social groups and he believes that scale of social health evaluates a part of person's health that shows person's satisfaction and dissatisfaction from life and social environment and in fact it includes the internal responses of person (feeling, thinking and behavior) (Larson, 1996, p. 183).

Finally a definition that is the basis of the present research is the definition that Keyes has been presented from concept of social health. In Keyes's opinion social health is "evaluating person's identification from way of his operation in community and quality of his relationship with others, relatives and social groups that he is the member of them" (Keyes, 2004, p. 83). Keyes knows social health with five dimensions that are as following:

Table 1. Definitions of social health dimensions by Keyes

\begin{tabular}{ll}
\hline \multicolumn{1}{c}{ Concept } & \multicolumn{1}{c}{ Definition } \\
\hline \multirow{3}{*}{ Social prosperity } & $\begin{array}{l}\text { Social prosperity includes evaluating potential ability and evolutionary path of community and believe in that the } \\
\text { community is evolving gradually and has some potential abilities to positive evolution that are identified through } \\
\text { social institutes and citizens (Keyes quoted by Farsi Nezhad, 2004, p. 88). }\end{array}$ \\
& $\begin{array}{l}\text { Social cohesion or correlation is comparable against frivolity in life and includes person's evaluation from } \\
\text { community in an understandable, predictable and sensible way and in fact it is perception that person has to quality } \\
\text { of organizing and managing his social world (Myrovsky and Rouse quoted by Sam Aram, 2013, p. 22). Approach } \\
\text { of social correlation propounds that social facts (such as society and group characteristics) are beyond the total of } \\
\text { people's characteristics; so people can't be understood without understanding groups that they are member of them } \\
\text { (Alestad quoted by Kheyrollah Pour, 2004, p. 56). } \\
\text { Integration or consolidation can convey uniformity of person and environment, attraction of person by environment } \\
\text { or internal attraction of environment by person and some commitments against his environment as a correlation and } \\
\text { responsible element (Tavassoli, 2003, p. 70). In Angel's opinion integration will be as emphasis on a set of }\end{array}$ \\
\hline
\end{tabular}


common values and purposes that are important for members of a group. These purposes and values play determinant role in live of that group. In fact social integration or consolidationis measurement for quality of people's relationships in the relation with society and community. People should try to create a sense of belonging to the whole world in them, not just to be dependent on unconditional loving family and friends. Healthy people feel there is an intersection between them and people who make social fact of them (such as their neighbors). Also integration is that grade which people feel they belong to their society and community (Keyes \& Shapiro, 2004, p. 46).

Social acceptance; people who have health dimension, understand community as a general and public set that has been formed from different people and trust others as people with capacity and kind and they believe that people Social acceptance can be effective and industrious. These people have desirable viewpoint to nature of human and feel comfortable with others. Social acceptance is the sense of acceptance of self. In social acceptance person has positive attitude and good feeling to self and pervious life and despite weaknesses and disabilities that he has, accepts all aspect of self (Keyes \& Shapiro, 2004, p. 49).

\section{Theoretical Considerations}

\subsection{Social Health}

Keyes believes that mental health, life quality and operation of person cannot be evaluated without consideration to social criteria and good operation in life is something beyond mental and emotional health and includes social involvements and conflicts. Therefore he knows social health the evaluation and identification of person from way of his operation in community and quality of his relationships with other people, relatives and social groups that he is the member of them. In the opinion of him and Shapiro a thing that gives meaning and richness to life is relatives, relationships and common experiences. So he gives topic of social health to person's ability in effective interactions with others and communities in order to make personal fulfilling relationships and do social roles (Samiei et al., 2010, p. 34).

He believes that conceptualizing mental health should be widespread so that to cover social health too. From a long time ago social health has been defined as being free from negative social modes such asalienation or chaos andnot necessarily that existence of psychological conditions to be basis of social health (Keyes, 1998, p. 133). While social health has been considered a lot in individual aspect (for example Ryff, 1996) also this belief has been propounded that equal attention should be paid to social nature of social health issue. In Keyes's opinion social health or lack of that had been obvious concern in classical Sociological theories.

Despite the importance of concepts such aschaos and alienation that have been concerned by Marx and Durkheim, they have discussed about multiple dimensions of positive social health. Social cohesion and integrity are some potential benefits of social life that means internal dependency and belonging feeling and common conscience feeling and collective destiny. Advantages of social life can be basis of presenting a universal definition from social health. Social health includes estimating condition and function of a person in society. In continue Keyes describes social challenges that form dimensions of social health.

Social health has been defined in this way: "valuation of condition of a person and hisproficiency in society" which this is a reflection of "positive social health" (Keyes, 1998, p. 122). This shows this truth that: a reflection of social health is reflection of people's perception from their experiences in social environment that is situated in conflict with social health criteria interpersonally; means criteria such as social support or criteria that take executive forms to themselves such as evaluations of social capital. So health and social health should be conceptualized in a way that to include person's self-confirming in social groups, validation and verification of this case for different people (Rosenfeld, 1997; quoted by Hatami, 2010, p. 54).

Keyes conducted two researches (one by using telephone poll and another with a self-written questionnaire) which were confirmers of social health: these researches presented some evidences for convergent validity among scales of social health and cases such as social participation, generator being activities, understanding limitations, satisfaction of life and happiness. Also Keyes found that social health is generally increased by increase of age and education level and he believed that skills, resources and experiences are increased by increase of age and help to people to cope with social challenges better.

While these scales of social health are in line with scales of spiritual health that lead to mental health, but they 
don't have overlap with them. In addition these scales just have correlation with optimism in minimalistic way. So results that Keyes receives show scales of social health in enough level indicate amount of resolving social challenges by people. He believes that social health is an achievement (Keyes, 1998, p. 133). Executing social health as a mental, physical and social function should present more considerable viewpoint about people's perception of their suitable function amount in their environment.

Laikouk and Berkman are other scholars who have evaluated social health. Laikouk defines social health as people's conditions and welfare in net of social relationships including family, community and nation. Also Berkman believes effect of social net in person's health includes educating participation morale and social involvements of person in social processes. Participation and social involvements arise from operation of potential connections in life activities.

Spending time with friends, presence in social functions, participation in social and job roles, tendency to religious activities and having fun with group are sensible samples of social involvement. So meaningfulness of roles such as social, job, family and parenthood roles are defined through opportunities that find by membership in social nets and through this the person's health is increased too. In addition to this participation within the net provides some opportunities for friendship, companionship and association that these behaviors, attitudes and connections give meaningfulness to person's life and this matter has great effect on his health (Berkman et al., 2000; quoted by Kheyrollah Pour, 2004, p. 43).

\subsection{Social Support}

Social support has been defined the amount of having endearment, companionship and attention of family's members, friends and other people. Some people know social support a social fact and some others know it due to person's perception (Ali Pour, 2006, p. 134). Social support has different forms such as informational, commutative, emotional, tools, substantial and social supports (Ferlander, 2003, p. 76). According to Kob's definition the social support mentions to amount of having endearment, assistance and attention of family's member, friends and other people.

House theory is one of relevant theories in social supports subject. According to House theory "social supports are often referred to done actions for a turbid person by family's members and friends, colleagues, relatives and neighbors. These actions are usually shown as tools help, social-emotional help and informational help".

According to this viewpoint, tools help is referred to provided materials and actions by others that make person able to do responsibilities related to usual role. Social-emotional help is referred to person's confirmations or love pretense, crying, trusting, sympathizing and belonging feeling to group. Informational help is referred to intellectual connections or revealing truth for existing problems such as advice and recommendations, personal feedback and information that may make life condition of person easier (House, 1981).

Social relationships are carriers of social support and social support models and theories describe and explain social relationships that provide support resources in form of weak and strong connections in relative structures, friendship or social nets. These theories and models in their description and explanation each one mentions to social support from different aspects based on a certain range of people's social relationships or whole their social relationships, two cases are mentioned in follow:

Direct effect model of social support: this model says the beneficial effects of social support are equal inlow stress or stressful conditions, direct effects of social support may act from several ways. For example people who have high social support, feel more belonging and self-esteem. A positive attitude that is created in such situation, ignoring stress amount, may be useful for person while it shows that high amount of social support causes to encouraging people to select healthier life methods (Sarafino, 2005).

"People's involvement in different social nets such as family, friendship and neighborhood nets, provides supportive resources that people achieve the desirable condition by more attraction in these nets that finally they obtain support and consequently health. Researches affected by direct effect model of social support say people who are in supportive nets, are less depressed and mainly they show better mental health than people who don't have such supportive nets" (Totis, 1988, p. 45).

Indirect effect model or buffering hypothesis: this model says that social support is mainly created when level of events increases mental pressure. In opinion of Cohn and Wills (1981), social support acts as the contour between stressful events and reaction to them and leads to debilitation of unsuitable responses to stress (Qodsi, 2003 , p. 54). In this model protection is done at least through two ways:

A) The first way includes cognitive evaluation, when person face stressful situation like financial crisis, people who have high social support, don't evaluate situation stressful much than people who benefit less support 
because they feel that they can cope with this crisis.

B) The second way includes adjusting reaction against situation that has been evaluated stressful. For example a person has high social support many has a friend that to present a suitable solution for his problem and convince him that the problem is not very important. People who have low social support don't have these advantages, for this reason the negative effects of stress are very more on them (Sarafino, 2005).

\section{Theoretical Framework}

Health is not only related to personal organic mode, but also it includes cultural, economic and social factors too. So in the research we had been trying to evaluate and study relationship of social support and social health. In this regard, to measure the dependent variable of the research means social health, following Keyes' classification of social health we have evaluated it in five dimensions. So Keyes's quintuple theory is used as definition model and presenting indexes.

Keyes evaluates social health and defines person's cognition of way of his operation in community and quality of his relationships with other people, relatives and social groups that he is as a member of them. He propounds his five factor model based on this, five factors of cohesion, acceptance, prosperity, participation and social correlation form indexes of health.

Among the propounded theories related to social health, the social net theory in the form of model of Berkman and others (2000) is used to evaluate effect of social support on social health according to direct effect model. In the mentioned theory the way of people's involvement in communities and social nets are explained. People are members of society that has been formed by connection with others, these connections form structural environment and make people's personal net that leads to provide functional support for people (Nabavi et al., 2010). Also the social net theory and Berkman's model are verifiers in order to express relationship between social support and social health. So according to Berkman's model and Keyes's social health theory the hypotheses of the research have been extracted from these two theories.

\section{Hypotheses of the research}

\section{*Main hypothesis}

It seems that there is relationship between social support and social health.

\section{*Subsidiary hypotheses}

1) It seems there is relationship between social support and social prosperity.

2) It seems there is relationship between social support and social correlation.

3) It seems there is relationship between social support and social adaptation.

4) It seems there is relationship between social support and social acceptance.

5) It seems there is relationship between social support and social participation.

\section{Methodology}

This research has been conducted in the social survey method and analysis unit and also level is person's observation. The intended information has been collected through questionnaire. The used questionnaire for the social support variable is a standard questionnaire that has been designed by a questionnaire by Wax et al. in three dimensions. A questionnaire that has been designed in five dimensions by Keyes was used for dependent variable means social health. The obtained alpha is 0.7 for both questionnaires that show high validity of the questionnaires.

The statistical population of the present research includes all citizens who are residents in Tehran in 2015 . Number of them is approximately 81254051 based on the obtained statistics from website of Iran's Statistic Center. 384 people were selected among this number as the sample that 16 people were added to size of the sample by predicting estimation error and probable abscission and 400 people have been determined as the main sample of the research. According to altered-being about 15 of questionnaires, 385 questionnaires were used in final analysis. It should be noted that the used sampling method had been as multistage cluster.

\section{Findings of the Research}

First table of indexes of central dispersal are mentioned in this part then analytical tables related to variables of the research. 
Table 2. Central statistics and dispersal of indexes related to dependent and independent variables

\begin{tabular}{|c|c|c|c|c|c|c|c|c|c|}
\hline Variable & Index & $\begin{array}{l}\text { Number } \\
\text { of items }\end{array}$ & Minimum & Maximum & Mean & Middle & Facade & $\begin{array}{l}\text { Standard } \\
\text { deviation }\end{array}$ & Numbers \\
\hline \multirow{5}{*}{$\begin{array}{l}\text { Social } \\
\text { Health }\end{array}$} & Social prosperity & 4 & 8 & 18 & 26.12 & 13 & 13 & 108.0 & 385 \\
\hline & Social conformity & 3 & 4 & 12 & 93.7 & 8 & 7 & 092.0 & 385 \\
\hline & Social solidarity & 3 & 4 & 12 & 93.7 & 8 & 8 & 065.0 & 385 \\
\hline & Social acceptance & 5 & 8 & 21 & 87.12 & 12 & 12 & 141.0 & 385 \\
\hline & Social participation & 5 & 5 & 22 & 81.9 & 9 & 9 & 223.0 & 385 \\
\hline \multirow{3}{*}{$\begin{array}{c}\text { Social } \\
\text { Support }\end{array}$} & Supporting Friends & 8 & 8 & 34 & 47.17 & 16 & 15 & 191.6 & 385 \\
\hline & Family support & 9 & 12 & 39 & 30.23 & 22 & 17 & 328.6 & 385 \\
\hline & Support from others & 6 & 7 & 27 & 40.14 & 14 & 13 & $4 / 383$ & 385 \\
\hline
\end{tabular}

In above table statistics of dispersal index of all dimensions of dependent and independent variables have been mentioned such as average, moderate, mode and standard deviation.

Table 3. Matrix of pair wise correlation coefficients among quintuple dimensions of social health

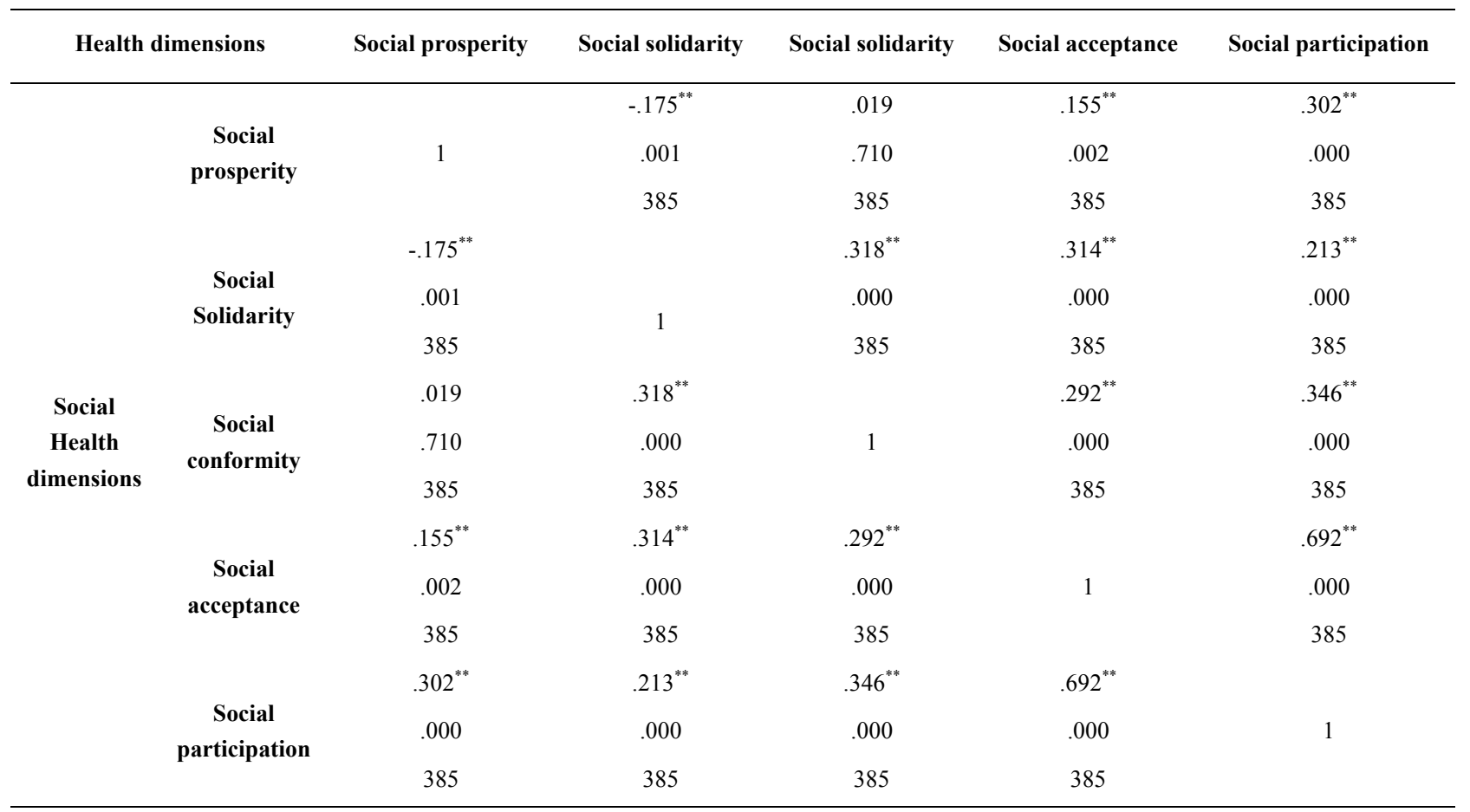

* In each part, values of first row are Pearson coefficient, values of second row are significant level and values of third row are sample volume.

The correlation test resulted from data related to social health indicates that all quintuple dimensions of social health are significant expect social cohesion correlation and social prosperity. 
Table 4. Matrix of pair wise correlation coefficients among triple dimensions of social support

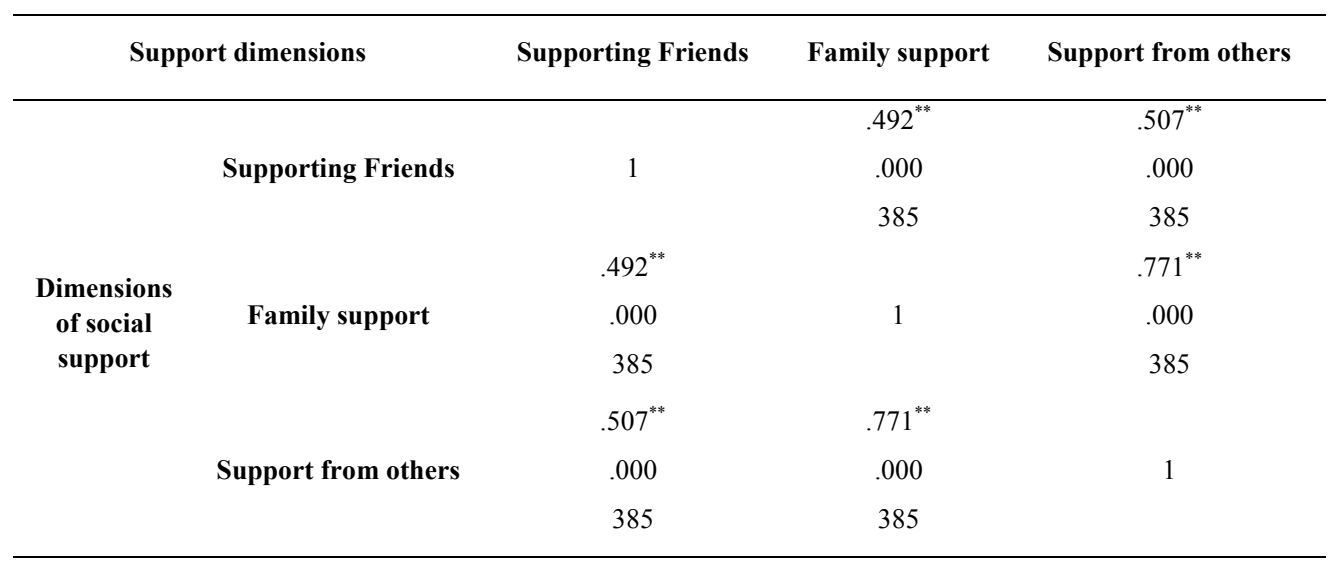

The correlation test resulted from data related to social support indicates that all triple dimensions of social support are significant.

Table 5. Correlation test among social support and social health

\begin{tabular}{cccc}
\hline Mean & Standard deviation & Number of respondents & Variables \\
\hline 17.55 & 368.14 & 385 & social support \\
90.49 & 668.10 & 385 & Social Health \\
& $\mathrm{Sig}=0.000$ & \multicolumn{2}{c}{ Pearson Correlation $=0.751$} \\
\hline
\end{tabular}

Pearson's correlation coefficient has been used to test relationship between social support and social health. The reason of using this test is due to measurement level of variables, because measurement level of both variables isdistance; so the most suitable test is Pearson's correlation coefficient. Data resulted from the research indicate the existence of relationship between these two variables, because the obtained significant level is less than 0.01 $(\mathrm{Sig}=0.000)$; means that there is relationship between social support and social health. The obtained correlation coefficient $(0.751)$ shows very strong correlation between the two variables.

Table 6. Relationship between social support and dimensions of social health

\begin{tabular}{cccc}
\hline Independent variable & \multicolumn{3}{c}{ Social support } \\
\cline { 2 - 4 } The dependent variable dimensions & Correlation & Significant & Number of samples \\
\cline { 2 - 4 } Social prosperity & 209.0 & 000.0 & 385 \\
Social Solidarity & 365.0 & 000.0 & 385 \\
Social conformity & 244.0 & 000.0 & 385 \\
Social acceptance & 588.0 & 000.0 & 385 \\
Social participation & 733.0 & 000.0 & 385 \\
\hline
\end{tabular}

First hypothesis: "there is relationship between social support and social prosperity".

Correlation value of these two variables is 0.209 . Direction of relationship is positive and its intensity is weak and it is significant in $\mathrm{P}=0.000$ level. This relationship shows that by increase of social support amount the social prosperity is increased too.

Second hypothesis: "there is relationship between social support and social correlation".

Correlation value of these two variables is 0.365 . Direction of relationship is positive and its intensity is medium 
and it is significant in $\mathrm{P}=0.000$ level. This relationship shows that by increase of social support amount the social correlation of people is increased too.

Third hypothesis: "there is relationship between social support and social adaptation".

Correlation value of these two variables is 0.244 . Direction of relationship is positive and its intensity is approximately medium and it is significant in $\mathrm{P}=0.000$ level. This relationship shows that by increase of social support amount the social adaptation of people is increased too.

Fourth hypothesis: "there is relationship between social support and social acceptance".

Correlation value of these two variables is 0.588 . Direction of relationship is positive and its intensity is strong and it is significant in $\mathrm{P}=0.000$ level. This relationship shows that by increase of social support amount the social acceptance of people is increased too.

Fifth hypothesis: "there is relationship between social support and social participation".

Correlation value of these two variables is 0.733 . Direction of relationship is positive and its intensity is strong and it is significant in $\mathrm{P}=0.000$ level. This relationship shows that by increase of social support amount the social participation of people is increased too.

Table 7. The coefficients of relative participation of multiple regression of social health (sample number: 385 )

\begin{tabular}{cccc}
\hline Independent variable dimensions & B & $\beta$ & significant \\
\hline Supporting Friends & 812.0 & 471.0 & 000.0 \\
Family support & 501.0 & 297.0 & 000.0 \\
Support from others & 307.0 & 126.0 & 019.0 \\
F test and total significant level & 33.177 & & 000.0 \\
R2 (coefficient of multiple determination) & & 579.0 & \\
\hline
\end{tabular}

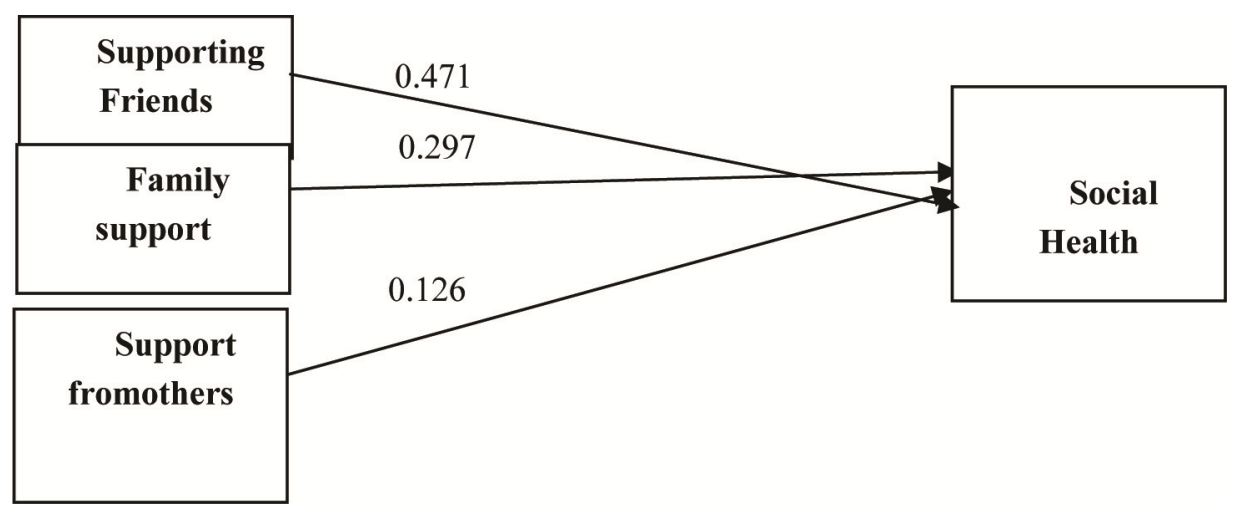

Figure 1. Analytical model

In above table, simultaneous effect and relative participation of dimensions of independent variable of the research on dependent variable (social health) have been mentioned by using regression coefficient. The Multiple determination coefficient shows total of relative participation of dimensions of social support on social health that it is approximately 0.58 . Total variance of social health has been explained by triple dimensions of the under evaluated social support. It should be noted that dimension of friends' support with regression coefficient of (0.471) is the biggest predicator of social health.

\section{Discussion and Conclusion}

In this research it has been tried to use Keyes's quintuple theory as the definition model and presenting indexes to measure the concept of social health as the dependent variable. Keyes evaluates social health and defines person's cognition of way of his operation in community and quality of his relationships with other people, 
relatives and social groups that he is as a member of them. He propounds his five factor model based on this, five factors of cohesion, acceptance, prosperity, participation and social correlation form indexes of health. Keyes evaluates social health and defines person's cognition of way of his operation in community and quality of his relationships with other people, relatives and social groups that he is as a member of them. He propounds his five factor model based on this, five factors of cohesion, acceptance, prosperity, participation and social correlation form indexes of health. The obtained results indicate some weaknesses and strengths in main and subsidiary dimensions of social health and social support in the under evaluated society. It means that there is a significant correlation between all quintuple dimensions of social health, there is no significant correlation just between social prosperity and social cohesion. Social support is one of important variables in social life that leads scholars of sociology to analyze theoretically in this field. In this regard social support has been considered as an effective variable on formation of quintuple dimensions of social health in the form of main hypothesis and subsidiary hypotheses. The data indicates the existence of relationship between these two variables and dimensions of social health.

Social support has been extracted from theory of social net and Berkman' model that was tested in relationship with social health. The relationship of this variable with each one of quintuple dimensions of health in the form of hypotheses showed that social support has positive correlation with all quintuple dimensions of social health. It means that amounts of prosperity, acceptance, correlation, adaptation and social participation are increased by increase of social support amount.

Existing relationship of social support with all dimensions of social health are situated in line with the social net theory. By inference of the social net theory it can be said that people's social health makes a dialectical interaction of people's relationship in two micro and macro levels. These interactions make structural environmental interactions that becomes underlie of functional support of people and in another level the received support becomes underlie of prosperity, correlation, adaptation, acceptance and social participation of people.

By adaptation of findings of the present research with pervious findings it can be said, the indicative results from relationship of social support and social health is situated in line with researches of Abbot et al. (2008). Also results of this research is situated in line with direct effect model of social support that believes that family, friendship and neighborhood relationships provide supportive resources that people obtain desirable condition by more attraction in these nets that finally they obtain support and consequently health.

According to direct effect model of social support, people who have high social support, feel more belonging and self-esteem. A positive attitude that this situation creates can lead to social prosperity as one of dimensions of social health. Sarafino believes that high amount of social support can lead to encouragement of people to select healthier life methods from this expression it can be concluded that high level of social support can be useful in social adaptation and acceptance and this the same results that the present research has achieved.

Beta coefficient resulted from regression test indicates the fiends' support has the most effect on social health and support of family and others are respectively in next priorities in effectiveness on social health. It seems that the obtained result is in conflict with researches of Larson (1996), Friedman (1992) and Sarafino (1994) who know the support of family in first level of effectiveness.

\section{References}

Akbariyan, M., Tabardarzy, A., \& Khaki, M. E. (2010). Public health, police and a sense of security. In Proceedings of the First National Seminar of Social Health, Ministry of Health, Treatment and Medical Education (pp. 92-109).

Alipur, A. (2006). Social support associated with immune markers in healthy subjects: A review of the overall impact. Iranian Journal of Psychiatry and Clinical Psychology (thought and action), 45, 134-139.

Farsi, N. M. (2004). Identity styles and social health and educational Khvdkaramdgy male and female high school students in Tehran (Master's thesis). Tehran University Faculty of Psychology, Tehran.

Ferlander, S. (2003). Health and well-being for people. Sidney Toronto.

Graham, A. V., Frank, S. H., Zyzanski, S. J., Kitson, G. C., \& Reeb, K. G. (1992). A clinical trial to reduce the rate of low birth weight in an inner city black population. Fam Med, 24(6), 439-446.

Hatami, P. (2010). The factors affecting the social health of students, with an emphasis on social networks. Faculty of Social Sciences of Allameh Tabatabaei University in Tehran.

Kangarooha, M. (2008). Examining the social health of students and expressive control of Allameh Tabatabai 
University (Master's thesis). Faculty of Social Sciences of Allameh Tabatabai University.

Keyes, C. M. (1998). Social well-being. Social Psychology Quarterly, 2, 121-140. https://doi.org/10.2307/2787065

Keyes, C. M., \& Shmotkin, D. R. (2004). Optimizing well-behng: The Emprical Encunter of two tradititins. Journal of Personality and Social Phchology.

Keyz, K. L. M., \& Shapiro, A. (2004). Social Health in the United States, a descriptive Hmh-Gyrshnasy (Hussein, Trans.). University of Chicago Press.

Khairallah, P. A. (2004). Social factors affecting mental health with an emphasis on social capital (master thesis). Faculty of Literature and Humanities, Martyr Beheshti University.

Larson, J. S. (1996). The word health organizations definishion health: Social versos spiritual health. Social Indicator Research. https://doi.org/10.1007/BF00300458

Nabavi, S. A., Hossein-zadeh, A., Hossein, H., \& Seyyede, H. (2010). Evaluation of social and economic factors affecting emotions social security. Applied Sociology, 40.

Rafiei, H. et al. (2010). Social health: Evidence from social definition circuit to circuit indicator (pp. 26-45). First national conference of social Samet, Ministry of Health and Medical Education.

Ryff, C. D. (1989). Happiness is everything, or is it? Explorations on the meaning of psychological well-being. Journal of Personality and Social Psychology, 57, 1069-1081. https://doi.org/10.1037/0022-3514.57.6.1069

Saburi, S. (2011). Social health status among employees of Education District 11 of Tehran (social sciences master's thesis). Payam Noor University.

Sadeghi, H. A. A. (1996). The general public then she. Shiraz University of Medical Sciences, Shiraz.

Sadeghi, M. R., Castonguay, S., \& Rojui, M. (1999). The impact of stress and social support on depression in the elderly. Journal of Cognitive, $3 \& 4$.

Sajadi, H., \& Sadrossadat, S. J. (2004). Index of Social Health. The Magazine of Political Information-Economic, $207 \& 208,244-253$.

Sam, A., \& Ezzat, A. (2009). A Pamphlet Social Health. Faculty of Social Sciences der Tbatayy, Tehran.

Sam, A., \& Ezzat, A. (2009). Investigate the relationship between public health and social security with an emphasis on community policing satisfaction. Journal of Social Regulation, 88, 14-29.

Samii, M., Rafiei, H., Amini, R. M., \& Akbariyan, M. (2010). Social health: The definition of evidence-based consensus on the index circuit, 2.

Sarafynv, E. (2005). Health Psychology (Ali Ahmad, Trans.). Tehran: Growth.

Tavassoli, G. (2003). Anomic society in terms of social participation, respect and social deviations in partnership with social damage. University of Tehran University, Tehran.

Tavassoli, G. (2003). Theory of sociology. Tehran: Publisher side.

World Health Organization. (2000). A glossary of health promotion. In Communication and Health Education. Tehran.

Zahedi, M. (1997). Human security, public health infrastructure.

\section{Copyrights}

Copyright for this article is retained by the author(s), with first publication rights granted to the journal.

This is an open-access article distributed under the terms and conditions of the Creative Commons Attribution license (http://creativecommons.org/licenses/by/4.0/). 